\title{
Imagens de um certo Brasil e redes de significância na tradução para o português de Là où les tigres sont chez eux, de Jean-Marie Blas de Roblès: emergência do exótico?
}

\author{
Images of a certain Brazil and \\ networks of significance in the \\ Portuguese translation of Là où les \\ tigres sont chez eux, by Jean-Marie \\ Blas de Roblès: emergence of the \\ exotic?
}

Raquel Peixoto do Amaral Camargo*

Resumo: Neste artigo nos ateremos a "imagens do Brasil" (SOUSA, 2004) e a "redes de significância" (BERMAN, 1995) que aparecem no romance Là où les tigres sont chez eux, de Jean-Marie Blas de Roblès, e observaremos suas refrações na tradução para o português, Lá onde os tigres se sentem em casa, de Mauro Pinheiro e Maria de Fátima do Coutto. É nosso objetivo perceber como se dá a criação de um Brasil exótico no romance e como esse exótico emerge e se reconfigura na tradução. Inicialmente, observaremos o processo criativo do autor que, mediante um movimento de reversão de expectativas, engendra a construção de redes de significância e de imagens do Brasil. Voltaremos, em seguida, o olhar para o texto traduzido, no intuito de perceber diferenças que reiterem ou

*Doutoranda no Programa de Estudos Linguísticos, Literários e Tradutológicos em Francês na Universidade de São Paulo - USP. E-mail: raquelcamargo_7@hotmail.com 
enfraqueçam as redes de significância do original. Apontaremos, por fim, algumas consequências advindas das diferenças encontradas.

Palavras-chave: Imagens; Brasil; Redes de significância; Literatura francesa; Tradução.

Abstract: In this article we will focus on the images of Brazil and on the networks of significance (Berman 1995) that appear in the novel Là où les tigres sont chez eux, by Jean-Marie Blas de Roblès, observing its refractions in the Portuguese translation, Lá onde os tigres se sentem em casa, by Mauro Pinheiro and Maria de Fátima do Coutto. It is our goal to show how the creation of an exotic Brazil takes place in the novel and how this exotic emerges and reconfigures itself in the translation. Initially, we will observe the creative process of the author: through a movement of reversion of expectations he engenders the construction of networks of significance and images of Brazil. Next, we will look at the translated text in order to perceive differences that reiterate or weaken the networks of significance of the original work. Finally, it will be pointed out some consequences arising from the differences that we found.

Keywords: Images; Brazil; Networks of Significance; French literature; Translation.

\section{Introdução}

O presente artigo se dedicará à análise de algumas imagens do Brasil - com foco na personagem do índio Aynoré - que aparecem no romance Là où les tigres sont chez eux, de Jean-Marie Blas de Roblès, e à observação de suas refrações no texto traduzido para o português: Lá onde os tigres se sentem em casa, de Mauro Pinheiro e Maria de Fátima Oliva do Coutto.

O conceito de imagens com o qual aqui se trabalha advém da imagologia literária, uma área do saber ainda hoje situada no campo da literatura comparada e que encontra em autores como Hugo Dyserinck ([1988] 2005), Manfre Beller (2007) e Daniel-Henri Pageaux (2012) - apenas para citar os mais contemporâneos - os seus principais teóricos. A imagologia literária tem por principal objeto de estudo "as imagens de países criadas e veiculadas pela literatura" (SousA 2004: 21), que ganham forma no amplo quadro do imaginário. Imaginário que, segundo Pageaux (1995: 85), se constitui como aquilo que "dá forma, conteúdo e expressão ao real". Situar as representações do estrangeiro advindas da literatura no campo do imaginário implica reconhecer que, além de individuais, fruto do processo 
criativo de determinado autor, essas representações também possuem um forte componente social - seria impossível imaginar um indivíduo capaz de fazer simbolizações sem estar sob a influência de uma sociedade e uma cultura. As representações literárias do estrangeiro estão, portanto, balizadas pelo contexto social, histórico, cultural e linguístico nos quais se inserem.

De uma perspectiva imagológica as imagens literárias podem ser pensadas como autoimagens, isto é, imagens que um determinado país faz de si mesmo e que são veiculadas pela sua literatura nacional, ou como heteroimagens, imagens de determinado país veiculadas pela literatura de um outro país, isto é, por uma literatura estrangeira. (SouSA 1996, 2004). No caso em questão, tendo em vista que o romance estudado é francês, as imagens do Brasil por ele veiculadas constituem heteroimagens brasileiras. Cabe apenas ressaltar, como lembra Maria João Simões (2011: 19), que entre auto e heteroimagens há relações de continuação, pois, em larga medida, as imagens que um país faz de si mesmo são (retro)alimentadas pelas imagens de si feitas por um país estrangeiro. É nesse sentido que as imagens brasileiras que emergem de Là où les tigres sont chez eux se alimentam de imagens literárias nacionais ${ }^{1}$, que, por sua vez, também são influenciadas por olhares externos ${ }^{2}$ - estrangeiros - para o Brasil. De modo que, nesse processo circular de trânsito de imagens, o olhar para si não se desvincula do olhar do Outro, ao contrário, toma-o como referência.

Paralelamente ao processo de delineamento de imagens, identificaremos, no texto original, redes de significância (BERMAN 1995, 1999) que aparecem em momentos de alta simbolização da obra; na sequência investigaremos os modos como essas redes se (re)constroem na tradução brasileira do romance. É também o processo criativo do autor que emerge dessa investigação, com a ironia que the é

\footnotetext{
${ }^{1}$ Como exemplo da atuação, até certo ponto implícita, de imagens literárias nacionais no romance francês, se pode pensar nas semelhanças entre a personagem de Nelson, o Aleijadinho, e personagens do romance Capitães da Areia (1937), de Jorge Amado. Ainda que tais similitudes não sejam apontadas explicitamente no romance de Roblès, algumas características de Nelson, o Aleijadinho, tais como o fato de ser cocho, o fascínio por Lampião e o seu ódio pelos representantes do poder institucionalizado no Brasil, remetem à construção das personagens de Sem-Pernas e Volta-Seca, do romance já mencionado de Amado.

${ }^{2}$ Um exemplo de como a literatura nacional também se vale de imaginários literários estrangeiros acerca do Brasil é encontrado no Relato de um certo oriente (1989), de Milton Hatoum. Nesse romance nos deparamos com o papagaio Laure, cujas características e a biografia remetem ao papagaio, proveniente das Américas, que aparece no conto Un cœur simple (1877), de Gustave Flaubert. Considerando que Milton Hatoum foi um dos tradutores do conto de Flaubert - cf. Três contos (2004) - é legítimo pensar que essas aproximações não sejam apenas uma coincidência.
} 
típica e com a reversão de expectativas que tantas surpresas pode causar nos leitores da obra.

A noção de redes de significância será trabalhada de acordo com elaborações de Antoine Berman feitas particularmente em dois livros: Pour une critique des traductions: John Donne (1995) e La traduction et la lettre ou l'auberge du lointain (1999). De acordo com Berman,

Toda obra comporta um texto subjacente, onde certos significantes chave se correspondem $e$ se encadeiam, formam redes sob a "superfície" do texto, isto é: do texto manifesto, dado à simples leitura. É o subtexto que constitui uma das faces da rítmica e da significância da obra ${ }^{3}$ (BERMAN [1999] 2012: 78, grifo nosso).

Percebe-se, pois, que o uso encadeado de determinados significantes em um texto contribui para a formação de subtextos ${ }^{4}$ que compõem tanto a rítmica como da significância de uma obra. Significância essa que pode ser apreendida mediante a identificação das "zonas significantes” (zones signifiantes), isto é: passagens na qual uma obra "se condensa, se representa, se significa ou se simboliza"5 (BERMAN 1995: 70, tradução nossa ${ }^{6}$ ). São nas zonas significantes que “[...] uma obra alcança a sua visada própria (não necessariamente aquela do autor) e seu próprio centro de gravidade" (BERMAN 1995: 70) ${ }^{7}$. As traduções que, por sua vez, não transmitem esses subtextos acabam por “[...] destruir um dos tecidos significantes da obra”.

Observaremos, neste trabalho, como a transmissão de algumas redes de significantes do texto original na/pela tradução atua na construção de miradas exotizantes para o Brasil - entendendo que a representação de um Brasil exótico

\footnotetext{
${ }^{3}$ No original, lê-se: "Toute ceuvre comporte un texte " sous-jacent", où certains signifiants clefs se répondent et s'enchaînent, forment des réseaux sous la "surface » du texte, je veux dire : du texte manifeste, donné à la simple lecture. C'est le sous-texte, qui constitue l'une des faces de la rythmique et de la signifiance de l'œuvre" (BERMAN 1999: 61).

${ }^{4}$ Os subtextos, no contexto em que são pensados por Berman ([1999] 2012), fazem referência aos textos que não podem ser lidos na superfície textual - isto é, aos textos implícitos - mas que podem ser acessados mediante uma leitura atenta à formação de cadeias de significantes de um texto literário. Em consonância com as elaborações de Berman, que situam as cadeias de significantes no plano dos subtextos, se tem a interpretação de Michael Rifaterre, retomada por Gérard Genette, segundo a qual "A intertextualidade é o [...] mecanismo próprio à leitura literária. Apenas ela, com efeito, produz a significância, enquanto que a leitura linear, comum aos textos literários e não literários, produz apenas o sentido" (RIFATERRE apud GENETTE 1982: 9).

5 "se condense, se représente, se signifie ou se symbolise" (BERMAN 1995: 70).

${ }^{6}$ A partir deste momento, todas as traduções cujas referências não forem mencionadas são de nossa autoria.

7 "[...] une ouvre atteint sa propre visée (pas forcément celle de l'auteur) et son propre centre de gravité" (BERMAN 1995: 70).

8 “[...] détruit l'un des tissus signifiants de l'œuvre” (BERMAN 1999: 62).
} 
faz parte da significância do romance em questão. Nesse sentido, por não analisarmos o ritmo que também pode advir da formação de cadeias de significantes no texto-fonte, chamamos as redes de significantes de redes de significância, no intuito de dirimir possíveis confusões.

O exotismo, por seu turno, figura aqui como uma chave de interpretação, portanto, de leitura do romance, que é ativada no original e também pode ser, de diferentes maneiras, acionada na tradução. A noção de exotismo, quando pensada no âmbito da literatura, designa o aparecimento do estrangeiro na paisagem geográfica, mas também histórica e cultural, de um texto literário (MOURA 1992). "Pintura do estrangeiro", representação da "cor local” do Outro, para falar com Jean-Marc Moura (1992), o exotismo aponta também para um “descentramento do olhar" (MOURALIS 1975: 67), pois a figuração do estrangeiro em uma obra literária produz um deslocamento no que concerne aos temas, questões e problemas abordados pela literatura. Mediante o exotismo literário, comumente relacionado a contextos de viagens ${ }^{9}$, o Outro adentra paisagens já conhecidas, passando a povoar cenários habituais e a pintá-los com uma coloração estrangeira.

Ora, se o exótico, aqui entendido como aquilo que é estranho, no sentido de externo e de não familiar à perspectiva do leitor visado por determinada obra, tem a vantagem de suscitar uma espécie de abertura de horizontes, uma disposição para ir ao encontro do Outro, ele também pode acarretar o desrespeito da alteridade. Conforme lembra Moura (1992: 8), nem sempre a alteridade do estrangeiro é respeitada em um romance. Como por exemplo, o persa de Cartas Persas (1721), de Montesquieu, é utilizado como um recurso para produzir novas visões sobre a sociedade francesa, mas o que está em jogo não é a sua alteridade, e sim o olhar distante que ele pode lançar para um cenário já habitual: Paris, a França etc. Nesse sentido ao passo que o exotismo pode figurar como uma celebração da diferença, e aqui se pode lembrar da concepção de Victor Segalen

\footnotetext{
${ }^{9}$ Não é por acaso que o exotismo ganha força no âmbito das "narrativas de viagem" produzidas por missionários, aventureiros e eruditos europeus à época do Renascimento. Importa lembrar que a figura do índio ocupa um lugar central nessas narrativas: se em Histoire d'un Voyage fait en la terre du Brésil (1578), Jean de Léry faz um retrato detalhado do nativo das terras brasileiras, no ensaio Des Cannibales (1580) Montaigne se dedica a traçar uma imagem do índio a partir de discussões filosóficas que opõem natureza à cultura. As descrições do índio brasileiro, provenientes das narrativas de viagem do século XVI, serviram de protótipo para diversos tipos de exotismo produzidos pela filosofia iluminista (século XVIII) acerca do nativo das Américas. O mito do "bom selvagem", por exemplo, que apresenta o índio americano "[...] liberado de todos os vícios da civilização" (MOURA 1992: 63), constituiu um tema fundamental no âmbito dessas produções.
} 
(1978) acerca do exótico - estética do Diverso -, ele também pode produzir visões redutoras, no limite clichês e estereotipadas, acerca do Outro ${ }^{10}$.

É um objetivo da investigação aqui proposta atentar para os modos como a formação de um Brasil exótico, mas não necessariamente clichê, se delineia no romance de Roblès, verificando, posteriormente, como a tradução transfere as redes de exotismo que participam da significância da obra. Mediante as transferências engendradas pela tradução e através de interpretações realizadas por leitores implícitos brasileiros, outras imagens do Brasil, mais ou menos exóticas, mas possivelmente diferentes, poderão ser aqui identificadas. Acreditase que a tradução pode não apenas encontrar e revelar a significância de uma obra, mas também produzir deslocamentos fundamentais para que novas leituras do original se estabeleçam.

Cabe, por fim, falando junto com Berman (1995), ressaltar a importância de realizar análises orientadas do texto-fonte, isto é, com foco em um determinado aspecto da obra, pois a partir dessas análises é possível lançar um olhar direcionado para a tradução, compreendendo como ela "enxerga" o original e como o traduz.

\section{Um índio romântico, uma etnóloga seduzida: tateando imagens, tecendo interpretações}

Moéma é uma personagem com uma visão um pouco romantizada do Brasil. Ao conhecer Aynoré, na saída de uma festa de forró em Canoa Quebrada, Moéma se deixa levar pela atmosfera mística do índio, mais propriamente pelas histórias de xamanismo e mitos por ele contados para explicar o surgimento do mundo. Romanticamente, a personagem acredita que o seu encontro com Aynoré a levará à realização de um antigo desejo: um retorno às suas ancestralidades. Atenhamo-

\footnotetext{
${ }^{10}$ Nesse sentido, situamo-nos aqui no domínio do que pode ser entendido como "alteridade": "1 - natureza ou condição do que é outro, do que é distinto, diferente; diversidade. 2 - situação, estado ou qualidade que se constitui através de relações de contraste, distinção, diferença" (HOUAISS online).
} 
nos a alguns trechos do romance, com o intuito de interpretá-los para mais bem compreender a trama e perceber quais elementos são por ela colocados em jogo ${ }^{11}$ :

(Quadro 1)

Au bord de l'eau on percevait un peu plus encore la violence du vent qui dispersait les dunes. Aynoré restait silencieux; de temps à autre, Moéma sentait sa main frôler la sienne tandis qu'ils s'éloignaient en titubant sous les bourrasques. Quelques centaines de mètres plus loin, ils s'étaient à demi couchés sur le sable, à l'abri d'une jangada tirée sur le rivage. Moéma avait roulé un joint. Dans l'assourdissante rumeur des vagues, quelque chose venu des premiers âges de la Terre, un vacarme incompréhensible et affolant les pelotonna l'un contre l'autre. Elle tira une première bouffée de la grossière cigarette qu'elle était parvenue à rouler malgré le vent, Aynoré fit de même et se mit à lui parler d'une voix douce: le monde avait commencé de cette même façon, avec une femme issue de sa propre nuit et un cigare magique...

Ses pensées s'exhalèrent sous la forme d'un nuage sphérique surmonté d'une tour, un repaire bombé comme l'excroissance du nombril sur un ventre de nouveau-né. Et en se déployant, cette bulle de fumée incorpora toute l'obscurité, de telle façon que les ténèbres y demeurèrent captives. Cela fait, Yebá Beló nomma son rêve «Ventre du monde ", et ce ventre semblait un grand village déserté. Alors elle voulut des gens là ou il n'y avait rien, et elle recommença à mastiquer l'ipadu en fumant son cigare magique... (ROBLES 2008: 386, grifo nosso).
À beira do mar, ficava ainda mais evidente a violência do vento que dispersava as dunas. Aynoré estava calado; de vez em quando Moema sentia a mão dele roçar na sua, enquanto se afastavam cambaleantes sob o vendaval. Algumas centenas de metros mais adiante, eles se estenderam sobre a areia, protegidos por uma jangada que repousava na praia. Moema tinha fumado um baseado. Sob o rumor ensurdecedor das ondas, que parecia vir das priscas eras da Terra, aquele estrondo incompreensível de assustador levou-os a se aninhar um ou outro. Ela deu um primeiro trago no baseado disforme que conseguira enrolar apesar do vento. Aynoré fez o mesmo e começou a lhe falar com a voz baixa: o mundo havia começado daquela mesma forma, com uma mulher surgindo da própria noite e com um charuto mágico...

Seus pensamentos exalaram sob a forma de uma nuvem esférica coroada por uma torre, um refúgio convexo como o umbigo sobre a barriga de um recém- nascido. $E$ ao se expandir, aquela bolha de fumaça incorporou toda a escuridão, de tal maneira que as trevas permaneceram cativas. Depois disso, Yebá Belô chamou seu sonho de "ventre do mundo", e esse ventre se assemelhava a uma grande cidade deserta. Então, ela quis ver gente lá, onde não havia nada, e começou a mascar o ipadu fumando seu charuto mágico... (ROBLES 2011: 358, grifo nosso).

(Quadro 2)

\footnotetext{
${ }^{11}$ Os trechos que seguem estão numerados para que se possa identificá-los quando eles aparecem na seção 3 junto às suas respectivas traduções.
} 
[...] il connaissait les mythes fondateurs des Mururucu, leurs rites, leurs danses et leurs chants traditionnels, savait invoquer les esprits transfigurés en autant de cailloux dans le hochet de calebasse et interpréter leurs messages dans le vrombissement des rhombes (ROBLES 2008: 386, grifo nosso).
[...] ele conhecia os mitos fundadores dos mururucus, seus ritos, suas danças e seus cantos tradicionais, sabia evocar os espíritos transfigurados sacudindo pedrinhas dentro de um chocalho de cabaça e interpretando suas mensagens no ronco dos maracás

(ROBLES 2011: 358, grifo nosso).

(Quadro 3)

[...] Partir avec Aynoré à la recherche de son peuple, retrouver ensemble cette communion originelle avec le fleuve, les oiseaux, les éléments ; Moéma se sentait tout à fait prête à ce retour vers la terre natale. Non comme ethnologue, mais comme Indienne de cœur et de conviction. En fervente des choses mêmes. Vivre c'était cela, ou rien du tout (ROBLES 2008: 389, grifo nosso).
[...] Partir com Aynoré em busca de seu povo, reencontrarem juntos aquela comunhão original com o rio, os pássaros, os elementos; Moema se sentia totalmente pronta para esse retorno à terra natal. Não como etnologista, mas como índia de coração e convicção. Fervorosa em relação às coisas em si. Viver era aquilo, ou então nada (ROBLES 2011: 361, grifo nosso).

Os trechos acima sintetizam a progressão da entrega, a princípio ingênua, de Moéma aos encantos de Aynoré. É possível identificar nessa abertura de Moéma para Aynoré alguns aspectos que compõem o horizonte de expectativas (romântico) da personagem: a busca por uma ancestralidade e uma comunhão original com a natureza; a crença na existência de um lugar primordial, de um tempo de felicidade genuína e o desejo de reencontrar esse lugar e esse tempo, pontos de partida há muito abandonados. Esse imaginário romântico, com suas voltas para a natureza e suas buscas por tempos primordiais, também é identificado por Celeste de Sousa (2004) em Iracema (1865), de José de Alencar. De acordo com a autora, alguns elementos desse romance convergem para a imagem de um Brasil primitivo: "a natureza verde, o clima bom, a vida natural" (SouSA 2004: 309). Há, portanto, uma coincidência entre as projeções de Moéma e o imaginário encontrado em uma obra representativa do romantismo literário brasileiro, o que permite falar em uma semelhança entre autoimagens do Brasil e hetero-imagens literárias francesas desse país.

Observa-se igualmente convergências entre a imagem do índio Aynoré que emerge dessas passagens - um ser de pureza, conectado com a natureza e com 
sua ancestralidade - e representações do "índio brasileiro" ${ }^{12}$ encontradas por Sousa (1996) em obras da literatura alemã, tais como A casa de Frieda Brunner (Die Weibsmühle, 1937), de Hans Friedrich Blunck; O Tigre Azul (Der blaue Tiger, 1938), de Alfred Döblin, e Macumba (Makumba, 1957) de Ulrich Becher. Para a autora, esses romances representam o “índio brasileiro" mediante atributos de simplicidade, hospitalidade, beleza, inocência e pureza, características que fazem desse tipo uma encarnação do modelo de homem edênico, primordial (SousA 1996: 151).

As semelhanças entre a imagem de Aynoré e os elementos observados por Sousa (1996) na caracterização do índio brasileiro na literatura alemã apontam para aproximações entre heteroimagens literárias alemãs do Brasil e heteroimagens literárias francesas desse mesmo país. Essas constatações levam a supor que imagens como as que aqui são abordadas, que constroem o "índio brasileiro" como um ser de inocência e pureza, retomando, inclusive, o mito do "bom selvagem”, circularam, e ainda circulam, através da literatura num processo contínuo de retroalimentação.

Voltemos agora a atenção para o quadro 3. As passagens em questão articulam uma discussão acerca do conhecimento organizada com base em uma polarização: de um lado um certo tipo de ciência cujos fundamentos se pode encontrar no pensamento positivista de Émile Durkheim ([1895] 2012), que proporciona um conhecimento com vistas à objetividade: o sujeito olhando para o seu objeto de estudo com um ar distanciado, não se implicando com ele e mantendo alguma imparcialidade; de outro lado, um conhecimento menos “científico" (associando aqui a ciência ao positivismo) que seria, na perspectiva de Moéma, mais intuitivo, mais genuíno e, por isso mesmo, mais verdadeiro.

Essa polarização entre o conhecimento científico de vertente positivista, que coloca o Outro como um objeto externo e faz do olhar científico um olhar distanciado, não implicado, e o conhecimento sem a mediação da ciência, que, na perspectiva da personagem, pode ser mais livre e mais verdadeiro, está plasmada implicitamente no desejo de Moéma de partir junto a Aynoré rumo à sua tribo,

\footnotetext{
${ }^{12} \mathrm{Na}$ perspectiva aqui adotada, não se trabalha com imagens tão amplas, tal como seria a do índio brasileiro, por isso optei por colocar a expressão entre aspas na sua primeira ocorrência no presente artigo. Tal expressão é utilizada no trabalho desenvolvido por Sousa (1996), o qual comporta o uso dessa perspectiva mais generalista.
} 
para vivê-la, e não para estudá-la em livros: “Moéma se sentait tout à fait prête à ce retour vers la terre natale. Non comme ethnologue, mais comme Indienne de cœur et de conviction. En fervente des choses mêmes. Vivre c'était cela, ou rien du tout".

Desse modo, consideramos que as frases acima, proferidas pelo narrador para "traduzir" o anseio da personagem, comportam uma parte importante da significância da obra, pois elas revelam uma construção de sentido que perpassa organização do romance e que aponta para o questionamento da separação entre sujeito e objeto. Assim, os significantes utilizados - "retour", "terre natale", "ethnologue”, “coeur”, “conviction” etc. - não foram escolhidos ao acaso. Ao contrário eles contribuem para a formação de um sentido maior, que ultrapassa a esfera da passagem ora em análise e se estende para o romance de um modo geral, sendo, por isso, considerados parte de uma escrita que possui um "alto grau de necessidade" (BERMAN 1995: 70). Por esse motivo, a passagem será retomada com uma atenção especial no âmbito das análises feitas da tradução - momento em que observaremos como a tradução transfere essas redes de significantes que compõem a significância do romance.

O modo polarizado como o conhecimento é organizado - observação distanciada versus experiência imersiva -, por sua vez, também contribui para uma exotização dessa parte da trama. O índio é visto por Moéma a partir de um olhar distanciado, exercendo um fascínio típico de paisagens exóticas, isto é, de cenários estrangeiros que encantam pela diferença que instauram na ótica de leitores habituados a paisagens locais. O lugar do familiar, do conhecido, do habitual, não é conferido ao índio pela personagem. Importa, no entanto, notar que a etnóloga romântica não pretende se regozijar com o fascínio que a diferença de Aynoré exerce nela, tal como os “proxenetas do exótico" (SEGALEN 1978) se comprazem em fazer. Ela quer, ao contrário, aniquilar toda a diferença, se tornando ela mesma índia e dirimindo, assim, a sua própria alteridade face ao indígena brasileiro.

Nesse sentido, retomando a discussão acerca da separação entre sujeito e objeto que certo modelo de ciências postula como condição para produzir conhecimento, observa-se que Moéma, em suas idealizações românticas, acredita que a única forma de acessar um suposto conhecimento "verdadeiro" acerca dos 
índios é tornando-se também índia. Com essa intenção, Moéma abandona o projeto científico de conhecer etnograficamente um grupo e descrevê-lo para os seus (academia, sociedade, governo). A personagem pretende fundir-se ao que antes era "objeto" de seus estudos. Queria agora "viver", nao conhecer: "Vivre c'était cela, ou rien du tout" - diz o narrador.

\subsection{Desconstruindo o romantismo de Moéma: a} reversão de expectativas

No ápice de seu delírio, tendo já cortado o cabelo como supunha ser o costume das mulheres da tribo de Aynoré, acreditando que formava com o índio um "casal primordial", Moéma tem a sua fantasia interrompida ao encontrar Aynoré tendo relações com Josefa, "a moça do buggy”, atrás das dunas. Após essa revelação, as imagens criadas por Moéma entram em colapso. Algum tempo antes, era ela que estava tendo relações com o índio, imersa em uma atmosfera de admiração profunda pela beleza sacra de seu corpo, como lemos na voz do narrador:

(Quadro 4)

[...] Son corps nu et bronzé lui inspirait moins de tendresse que de respect, une sorte d'estime confinant au sacré, à la vénération. De tout ce qu'il avait dit la veille, elle ne gardait qu'une impression d'efflorescence, quelque chose comme l'envol ralenti d'un perroquet, la trace rouge et or du paradis perdu (ROBLES 2008: 593).
[...] Seu corpo nu e bronzeado lhe inspirava menos ternura do que respeito, uma espécie de estima confinada no sagrado, na veneração. De tudo o que ele dissera na véspera, ela guardava apenas uma impressão de eflorescência, alguma coisa como o revoar vagaroso de um papagaio, o vestígio vermelho e dourado do paraíso perdido (ROBLES 2011: 415).

O sagrado, o voo lento de um papagaio e o vestígio vermelho do paraíso perdido se perdem para sempre após Moéma presenciar Aynoré e Josefa juntos, apenas protegidos dos olhares alheios por algumas dunas, na crueza de uma cena muito mais profana do que sagrada - para trabalhar com as imagens duais que nos propõe o romance. 
Adentrando na trama, percebemos que Aynoré aprendeu a vender uma imagem de si para atrair a atenção de turistas que frequentavam a região. Não existia, de fato, um profundo amor pela cultura de sua tribo e nem mesmo uma identificação com ela. Tampouco a identidade indígena que ele adotava era "verdadeira", no sentido de espontânea e genuína. Moéma, estudante de antropologia com uma visão romantizada dos índios, é a presa perfeita para os encantos de Aynoré. Ela não apenas se apaixona pela criação dessa imagem, mas, como diz o narrador (2008: 517), se convence de corpo e alma de que partirá como uma Iracema para cumprir o seu destino final junto à tribo de Aynoré, na Amazônia. O "truque" do índio já era um velho conhecido de Marlène, uma travesti amiga de Moéma, moradora de Canoa Quebrada. Como pode ser acompanhado no quadro 5, Marlène desmascara o índio para Moéma e traz um pouco de lucidez ao que ela viveu:

(Quadro 5)

- C'est son truc pour emballer les filles. Un bouquin qu'il a trouvé : les légendes indiennes, les rituels chamaniques, le déluge... tout est dedans. Du pipeau, ma fille. Il est à peine indien, et pas plus chaman que toi et moi... Sa mère était entraîneuse dans un bar de Manaus, quant à son père, c'est même pas la peine d'en parler : elle a jamais su lequel c'était de tous les ivrognes avec qui elle couchait...

- C'est pas vrai, balbutia Moéma en redoublant de sanglots. Tu mens! (ROBLES 2008: 518).
- É a estratégia dele para ganhar as moças. Ele achou um livro: lendas indígenas, rituais xamânicos, o dilúvio... Tirou tudo isso de lá. Papo- furado, querida. Ele nem é muito índio, e ainda menos xamã... A mãe fazia programa num bar de Manaus, enquanto o pai ... nem vale a pena falar: a mãe nunca soube quem era entre todos os bêbados com quem tinha ido para a cama...

- Não é verdade - balbuciou Moema, chorando ainda mais. - Você está mentindo! (ROBLES 2008: 481).

No ápice do seu desencantamento, como quem é forçada a sair de um sonho, Moéma volta decepcionada para Fortaleza, cidade onde morava, e é obrigada a encarar a realidade de sua desilusão. Nas palavras do narrador, "Foi como se toda a Amazônia evaporasse diante de seus olhos” (ROBLES 2011: 480) ${ }^{13}$.

13 “Ce fut comme si l'Amazonie tout entière se volatilisait devant ses yeux" (ROBLES 2008: 517). 


\section{Imagens de palavras: quais desenhos? Quais representações do Brasil?}

Quais imagens emergem da narrativa desse encontro, com seus desencontros e decepções? Como significar a construção da imagem de Moéma, brasileira, filha de um francês correspondente de imprensa no Brasil e de uma paleontóloga professora na Universidade de Fortaleza, como uma personagem a tal ponto romântica que suas atitudes podem mesmo ser consideradas ingênuas? Quais leituras podem ser feitas da esperteza e insensibilidade do índio Aynoré no que concerne à questão indígena? Cabe, em um primeiro momento, considerar que seria mais comum, considerando as informações que temos a respeito do que fazem os antropólogos e das imagens que conhecemos do índio na literatura brasileira, esperar que a construção dessas personagens se desse de modo contrário: que a inocência, o romantismo e a busca pela ancestralidade fossem relacionadas à figura de Aynoré e a desconfiança e o descrédito de uma imagem romantizada do índio aparecessem na personagem de Moéma. Afinal, a desconstrução de estereótipos indígenas deveria ser um tema que se supõe presente em um curso de antropologia. Siga-se, portanto, para algumas possíveis leituras dessas inversões.

Considerando as passagens que retratam Moéma e Aynoré, percebe-se que há um encontro que funciona mais na base de desencontros e desentendimentos do que num registro de encantamento e epifania compartilhada. 0 encantamento que se constrói encanta apenas Moéma, que é mais vítima de si mesma do que do índio. A estudante de antropologia tinha uma imagem romantizada do índio brasileiro, incompatível com seu lugar de etnóloga. Aynoré, por sua vez, longe de apresentar qualquer sentimento de culpa por uma falta de apego às suas origens, brinca com sua autoimagem para enganar os turistas que frequentavam Canoa Quebrada à procura do exótico, do "verdadeiro Brasil". E aqui o exótico se relaciona com uma busca pela estrangeiridade dentro de paisagens locais, isto é, brasileiras, pois os turistas frequentadores da praia eram igualmente brasileiros. Nesse sentido, cabe retomar a definição do prefixo "exo", da palavra "exotisme" 
(exotismo), tal como exposta por Victor Segalen (1978): “Definição do prefixo Exo na sua maior generalização possível. Tudo que está “fora” do conjunto de nossos fatos de consciência atuais, cotidianos, tudo que não é nossa "Tonalidade mental" habitual”"14 (SEGALEN 1978: 33).

Mediante o recurso a uma ironia profunda, vemos aqui uma atualização da imagem do encontro entre europeus e ameríndios, Moéma representando os primeiros. Mesmo sendo brasileira, Moéma é filha de francês e tem acesso a um tipo de saber que boa parte da população brasileira não possui no momento em que se passa a história, não apenas por conviver com um pai culto e com perfil acadêmico, mas também por ser estudante universitária em uma época na qual o ensino superior brasileiro não era uma realidade para a maioria da população ${ }^{15}$.

Ao repor em presença, de forma simbólica, o europeu colonizador e o índio colonizado, é mais uma vez a perspectiva do europeu que parece prevalecer. Vemos o tempo todo o índio na visão de Moéma, não na sua própria visão. É Moéma que diz Aynoré, que o enxerga, que constrói a sua imagem. Assim como, por muito tempo, foram estudadas as cartas dos jesuítas europeus que aqui chegaram para desbravar as Américas e escreveram sobre os índios que encontraram, deixando assim o legado das suas impressões e seus pontos de vista sobre os povos ameríndios ${ }^{16}$. Os jesuítas europeus disseram os índios e as suas palavras se espalharam não apenas pela Europa, mas também pelo continente americano. 0 movimento contrário, no entanto, não tem uma história tão consolidada. 0 ponto de vista dos índios sobre os europeus, ou sobre eles próprios - sua autodeterminação, a capacidade de dizer quem são se valendo de suas próprias vozes - não foi tão disseminado, ou mesmo estudado, como foi (e continua sendo) o conhecimento produzido no sentido Europa-América ${ }^{17}$.

\footnotetext{
14 "Définition du préfixe Exo dans sa plus grande généralisation possible. Tout ce qui est "en dehors "de l'ensemble de nos faits de conscience actuels, quotidiens, tout ce qui n'est pas notre "Tonalité mentale» coutumière" (SEGALEN 1978: 33).

${ }^{15}$ Para as vinculações entre literatura e mundo não ficcional, entre a dimensão interna da obra e a dimensão externa (o social), ver: CANDIDO 2000.

${ }^{16}$ Lembre-se aqui a já tão estudada carta de Pero Vaz de Caminha (1500), considerada um documento fundador a posteriori do Brasil - tendo em vista que foi descoberta tardiamente, no século XVIII - e todos os conhecidos relatos produzidos pelos capuchinhos acerca de diversos aspectos da vida e cultura dos ameríndios - cf. AMOROSO 1998.

${ }^{17}$ Um exemplo da ocidentalização do conhecimento e do seu sentido de produção (da Europa para outros continentes do mundo) pode ser encontrado em Edward Said ([1978] 2007). Em seu livro Orientalismo, Said nos mostra como boa parte do imaginário que circula no Ocidente acerca do chamado Oriente foi forjado com base no olhar ocidental para o mundo oriental. O próprio Oriente, lembra Said (2007), é uma construção - e
} 
Porém, o ponto de virada da história, que faz emergir imagens inusitadas em Là où les tigres sont chez eux, se dá quando o leitor descobre, contrariando todas as expectativas e imagens construídas, que é o índio que apreende Moéma, não o contrário. É Aynoré que conhece e enxerga Moéma, com toda a relação de poder aí implicada. Esse é, pois, o momento em que narrativa gera um inversão de expectativas nos leitores: a partir de sua esperteza, Aynoré acessa o fascínio de Moéma e seu apego a uma certa identidade indígena, por ele próprio não tão valorizada, e se vale disso para uma brincadeira de sedução. Com essa inversão, outras indagações se instalam, suscitando novas leituras da trama: quem é mesmo que busca o exótico? Que lugar ocupa o nativo nessa narrativa? Ele pode de fato ser enxergado por alguém "de fora”?

Mesmo se recusando a ser tratada como uma turista, Moéma acaba por representar, na lógica da trama, um olhar “de fora”, pois não pertence à comunidade de Canoa Quebrada, que funciona com base em uma dinâmica diferente da urbanizada Fortaleza do fim dos anos $1980 \mathrm{com}$ a qual a personagem está habituada, e onde se insere por via do mundo acadêmico, representado pela universidade dessa cidade $^{18}$. Importa enfatizar, ressaltando o recurso à ironia por parte de Roblès, que a personagem parecia se sentir legitimada para conhecer "de fato" Aynoré, pela relação intelectual que mantinha com a causa indígena no Brasil, sendo inclusive uma militante dessa causa. No entanto, era Aynoré que estava "estudando" Moéma, tão bem analisada que pôde até mesmo ser enganada. Assim, o que os movimentos da história parecem nos dizer é: o exótico está mais no olhar daquele que constrói e busca esse exótico do que propriamente nas pessoas e corpos em que as diferenças se instalam e ganham concretude. Em outras palavras, o exótico se constrói mediante um olhar, ou, se preferirmos, um

também uma invenção - do Ocidente. Cabe, no entanto, ressaltar, as perspectivas de estudos que vêm ganhando espaço em determinadas vertentes da antropologia, tal como aquela na qual atua Eduardo Viveiros de Castro e outros autores, no âmbito das quais vem sendo desenvolvida uma importante atenção ao pensamento indígena de povos ameríndios - cf. ViVEIROs De CASTRO 2004, 2008.

${ }^{18}$ Mais uma vez, as informações trazidas concernem à dimensão interna da obra e igualmente à sua dimensão externa, isto é, o social que a envolve e no qual ela se insere. Se é verdade, como mostra Antonio Candido (2000), que essas vinculações não podem ser negadas, essa verdade é ainda mais explícita no livro em questão, pois essas dimensões já se apresentam articuladas. Por exemplo, a Fortaleza descrita no romance é a Fortaleza que conhecemos dos anos 1980, mas não apenas isso, ela é também a cidade tal como ficcionalizada por Roblès e tal como ele a elabora literariamente. 
regime de olhar. O Brasil “pelos seus" seria, talvez, menos exótico do que supõem aqueles que o enxergam de uma perspectiva estrangeira ${ }^{19}$.

É importante lembrar que Moéma pretendia mostrar a Roetgen, personagem de um etnólogo francês, o "Brasil de fato", que ganha contornos na simplicidade da praia de Canoa Quebrada. Aynoré, com um certo deboche pelos deslumbres da estudante de antropologia, brinca com o imaginário e as expectativas que o acompanham. A pergunta que parece aflorar é: estariam mesmo, Moéma e Roetgen, por conviverem com nativos de Canoa Quebrada, conhecendo o "Brasil de fato" ou apenas alimentando o horizonte de expectativas que já possuíam e que tornavam o seu olhar direcionado demais para o que buscavam e esperavam encontrar? E seria mesmo possível conhecer esse "Brasil de fato" tal como Moéma, em sua juventude acompanhada de certa ingenuidade, acreditava ser?

Indagação semelhante move Sousa (1996) a mostrar que, nas obras alemãs por ela estudadas, as imagens do Brasil são permeadas pelo horizonte de expectativas dos europeus “descobridores" das Américas, que enxergavam mais as suas próprias projeções e mitos do que propriamente a nova realidade com a qual se deparavam ${ }^{20}$. Em certa medida, a imagem que Moéma tem do índio se assemelha à forma como, de acordo com Sousa (1996), a imagem do índio brasileiro se elabora em obras de literatura alemã que retratam o Brasil: mediante a projeção de valores eminentemente europeus. Essa similaridade remete, mais uma vez, à circularidade das imagens em questão. Ao fim do capítulo no qual analisa a figura do índio, a autora conclui:

A figura examinada nesse capítulo resulta da projeção dos valores da cultura europeia sobre um ser desconhecido. Nas obras estudadas, o índio é, assim, um elemento a mais, utilizado para caracterizar a paisagem primeva e edênica do Brasil. (SOUSA 1996: 167)

\footnotetext{
${ }^{19}$ Sendo também o autor do livro um estrangeiro, tentando, talvez, elaborar literariamente a própria reversão de expectativas que o seu imaginário de Brasil pode ter sofrido com a sua experiência de morar e trabalhar nesse país, pode-se pensar que ele também se implique nesses jogos e armadilhas suscitados no/pelo encontro com o Outro.

${ }^{20}$ A tese segundo a qual a imagem do índio "selvagem" se antecipa no imaginário europeu, sendo, portanto, anterior ao próprio encontro dos brancos com os índios, se encontra em Sérgio Buarque de Holanda (1959), autor com o qual Celeste Ribeiro de Sousa trabalha em seus textos.
} 
Cabe, porém, ressaltar, e nisso reside um aspecto inovador da obra de Roblès, que algumas diferenças surgem da imagem do índio Aynoré proveniente das passagens aqui analisadas. A começar pelo fato de que a "projeção dos valores da cultura europeia sobre um ser desconhecido", para retomar as palavras de Sousa, resulta em um completo desencontro. Esses valores são chamados pela autora de europeus, mas também podemos chamá-los de ocidentais, levando em consideração a amplitude da sua disseminação. O (des)encontro de Moéma com Aynoré mostra que essa projeção não funciona, isto é, ela não é o melhor caminho para conhecer e se relacionar com o Outro. Ao contrário, ela acaba por ser uma fonte de mal-entendidos que não gera um conhecimento de via dupla. Essa imagem literária, que emerge de forma brincalhona, irônica, mas também trágica do ponto de vista da personagem Moéma, é em si própria inovadora.

As relações entre o Velho e o Novo mundo, simbolizadas no encontro já aqui descrito e analisado, fazem parte da significância do romance ora em questão. É nesse sentido que, no âmbito da tradução, nos ateremos às redes de significantes que participam da construção dessa significância, percebendo de que modo a tradução pode deslocar sentidos e mesmo produzir novas (diferentes) interpretações da obra aqui estudada.

\section{Traduções: outras imagens? Outras}

\section{diferenças?}

Voltemos agora o olhar para o romance traduzido, observando escolhas tradutórias ali realizadas e considerando as suas implicações nas construções de sentido do texto. No quadro ${ }^{21}$, na tradução de "on percevait un peu plus encore" (ficava ainda mais evidente) e “Aynoré restait silencieux" (Aynoré estava calado), observa-se uma mudança sutil do registro do texto original, que é marcado por uma poeticidade e um lirismo que se refletem no tempo verbal utilizado, o imperfeito (imparfait), e também nas escolhas lexicais, como no uso da palavra

\footnotetext{
${ }^{21}$ As citações que aparecem nesta seção são as mesmas da seção 1 e também aparecem na mesma sequência. Basta, portanto, que o leitor retome os quadros da primeira seção para recuperar o contexto das frases citadas.
} 
"silencieux". O texto traduzido se vale de um registro mais neutro desse ponto de vista, isto é, menos marcadamente poético, haja vista a escolha da palavra “evidente" e da palavra “calado", esta última traduzindo "silencieux". Essa mesma questão também pode ser observada na tradução de “ils s'étaient à demi couchés sur le sable" (eles se estenderam sobre a areia). Neste caso, a imagem da dobra, que pode remeter a um certo acolhimento (“demi couchés”), não aparece na tradução. Observa-se também a opção de traduzir o tempo verbal "plus que parfait" ("s'etaient à demi couchés") pelo pretérito perfeito (se estenderam), que pode igualmente ocasionar uma mudança de registro, deixando o texto menos lírico, mas não implicando em uma mudança fundamental no sentido da cena, posto que, tanto no texto em português como no texto em francês, a ação está localizada no passado.

Já as diferenças encontradas nas passagens que seguem (ainda referentes ao quadro 1) interferem de maneira mais direta nas interpretações possíveis da trama, se mostrando relevantes para a visada que aqui buscamos desenvolver: "[Aynoré] se mit à lui parler d'une voix douce" ([Aynoré] começou a the falar com a voz baixa). A tradução de "voix douce" por "voz baixa”, nesse contexto, parece suscitar, senão uma quebra, pelo menos o enfraquecimento de uma imagem que emerge com muita força no original. "Voix douce" se coloca, novamente falando com Berman (1995), como significantes importantes na composição zona de significância dessa passagem da obra. Lembre-se que de acordo com o autor, algumas zonas possuem um alto grau de necessidade em um texto, isto é, foram escritas de uma maneira, e não de outra, por um motivo específico. Há também passagens que apresentam um certo grau de aleatoriedade, isto é, foram escritas de determinada maneira não por um motivo específico, pois poderiam ter sido escritas de outro modo sem afetar o conjunto da obra. Esse jogo entre o necessário e o aleatório compõe boa parte das obras literárias.

Para a imagem que compõe o núcleo central dessa trama, e que é acompanhada de questões subjacentes (questões que não necessariamente aparecem na superfície do texto, mas que um exercício de interpretação pode trazer à luz), traduzir a palavra “douce” pela palavra "baixa” faz diferença. "Voz baixa", como equivalente de "voix douce", tira a força de uma imagem do índio que vai sendo construída pouco a pouco mediante a narrativa do encontro entre 
Moéma e Aynoré. Senão, vejamos alguns significados presentes no campo semântico de “douce”:

Qui produit une sensation agréable au toucher : le doux contact de la soie. Qui procure une sensation agréable au goût ; suave : le miel est doux. Qui n'a rien de trop intense, de violent ou d'accentué : une douce chaleur. Qui n'est ni brusque ni saccadé, qui se passe sans heurts, sans à-coups : un démarrage très doux (LAROUSSE online).

Sens 1 : d'une saveur délicate, agréable ;

Sens 2 : d'une sensation agréable au toucher ;

Sens 3 : qui cause une sensation de bien-être ;

Sens 4 : qui n'est pas brusque, pas violent (LINTERNAUTE online).

(...) qui est agréable à l'oreille en raison de son harmonie, de sa faible intensité. (Quasi-) synon. Mélodieux, suave (CNRTL). ${ }^{22}$

Percebe-se que o campo semântico da palavra em francês contribui para a criação da imagem de um índio delicado, suave, de falar doce e calmo. Uma voz que exala romantismo é que dá o tom da passagem. Romantismo esse que é mais dificilmente captado na expressão "voz baixa”, que, mesmo remetendo a algum tipo de educação ou pudor, não capta tão diretamente a delicadeza de “douce”.

Prosseguindo com as análises do trecho, observa-se que a passagem “le monde avait commencé de cette même façon, avec une femme issue de sa propre nuit et un cigare magique" (quadro 1), traduzida como "o mundo havia começado daquela mesma forma, com uma mulher surgindo da própria noite e com um charuto mágico", também faz parte da zona de significância da obra. Nesse sentido, a omissão do possessivo "sa" (sua) retira uma dimensão mágica da entidade Yebá Beló. Ao observar o texto em francês, vê-se que ela não surge da noite, mas da sua própria noite. A construção da frase sugere que, como o Deus cristão, Yebá Beló surge de si própria, isto é, ela se gera e está presente no seu próprio começo. Esses aspectos ressaltam a dimensão mística da história contada por Aynoré, contribuindo para a imersão e o encantamento de Moéma. Tanto a tradução de "voix douce" por "voz doce" como de "sa propre nuit" por "própria noite" são detalhes que, dentro da chave de leitura com a qual aqui se trabalha,

${ }^{22}$ Todas esses significados foram retirados de dicionários online a partir da entrada doux/douce. 
podem reforçar ou suavizar a imagem romântica do índio. No caso em pauta, suavizam.

Nas passagens ao fim do quadro 1, chama a atenção a tradução do verbo "déployer" ("en se déployant") pelo verbo "expandir" (e ao se expandir), posto que, considerando o campo semântico do verbo francês ${ }^{23}$, "expandir" acaba por não apenas captar a imagem que se forma no texto original, mas melhorá-la. Sendo que "expandir" é um dos sentidos que compõe o verbo "déployer", os tradutores, ao escolhê-lo, clarificam o texto ${ }^{24}$. É possível perceber que a imagem de uma bolha que se expande é perfeitamente coerente com o fato de essa mesma bolha incorpora toda a escuridão ("E ao se expandir, aquela bolha de fumaça incorporou toda a escuridão"). Pode-se afirmar que a escolha dos verbos "expandir" e "incorporar", que nesse contexto aparecem como perfeitamente adequados à composição da frase, corrobora para a criação de uma rede semântica no próprio texto traduzido.

Do ponto de vista adotado neste artigo, na frase "[...] elle recommença à mastiquer l'ipadu", a escolha de traduzir o verbo "recommença" por "começou" marca a tradução e constitui uma diferença notável. "Recommença" comporta o sentido de começar de novo, "commencer de nouveau, refaire" (LINTERNAUTE online). 0 verbo utilizado no texto em francês traz uma dimensão de necessidade, no sentido já explicitado acima, isto é, de comportar um uso necessário, e não aleatório. "Recommença" reforça a dimensão circular do mito de Yebá Beló, dimensão essa que remete a uma existência contínua, sem começo, meio ou fim. Nesse sentido, podemos dizer que Aynoré conta que Yebá Beló recomeçou (e não começou) a fumar o seu charuto mágico porque não se pode encontrar o momento em que ela o fumou pela primeira vez, já que, de acordo com o mito, ela está e sempre esteve sendo e existindo. Assim, trata-se aqui também de uma escolha no texto original que reforça as redes semânticas que nele se constroem e que corrobora com a formação de imagens de coloração romântica, mística, ancestral.

\footnotetext{
${ }^{23}$ De acordo com o dicionário Linternaute online, tem-se: "Étendre, développer, ouvrir ce qui était plié, roulé: Déployer ses ailes. Manifester quelque chose, l'étaler dans toute son intensité ; montrer, manifester. Déployer une activité fébrile. Faire passer des troupes d'une formation de marche ou de transport à une formation de combat".

${ }^{24}$ De acordo com BeRMAN (1999: 54) a clarificação faz parte de um dos procedimentos tradutórios caracterizados como deformantes do texto-fonte. No entanto, no caso em questão, a clarificação advém de uma tradução que se pode dizer precisa, e não de explicitações exaustivas com o objetivo de tornar mais claro o texto-fonte. Em outras palavras, a tradução suscitou esse efeito, mas não precisou glosar para isso.
} 
A escolha da tradução, nesse caso específico, enfraquece essa rede, tornando-a menos visível.

Prosseguindo com o cotejo, observando as passagens "[...] dans le hochet de calebasse" e "le vrombissement des rhombes" (quadro 2), percebe-se que as imagens veiculadas no texto em português, mediante a escolha das palavras “chocalho" e “cabaça” e da expressão "ronco dos maracás", traduzem imageticamente a atmosfera exótica suscitada pela presença (e pelo discurso) do índio - mais uma vez, não se trata de dizer que a figura do índio é necessariamente exótica, ela chama o exótico nesse contexto pela diferença, em certa medida caricatural, que vai se organizando em torno do índio. Ainda que “rhombes" e "maracás" não se refiram necessariamente ao mesmo instrumento musical, a tradução capta o que há de significante para a trama do romance na presença desses instrumentos: a sua relação com a invocação de espíritos e a dimensão de ancestralidade e de alteridade que a cena comporta.

Como já mencionado no início do artigo, consideramos que as passagens do original em destaque no quadro 3 retêm a zona de maior significância do trecho em questão. Elas dão a conhecer não apenas o desejo de Moéma, mas também uma certa dicotomia presente na construção dos personagens, que oscilam entre uma ou outra vontade desmesurada, quase nunca encontrando uma "terceira via". Nesse contexto, a tradução de "ethnologue" por etnologista causa um estranhamento, pois "ethnologue", que encontra um correspondente direto em português na palavra etnóloga, corrobora um sentido implícito do texto que é a remissão a discussões no campo das ciências sociais. Nessa área, a palavra etnóloga é bem mais usual do que a palavra etnologista. 0 uso da palavra por parte do autor/narrador denota um conhecimento e uma inserção nesse campo que não é transmitido mediante o uso da palavra etnologista. Assim, a palavra “ethnologue" é importante para a significância do texto, ela possui um grau de necessidade (não foi usada aleatoriamente) e corrobora com redes subjacentes que se constroem, principalmente, mediante a veiculação implícita da discussão acima pontuada acerca dos modos de conhecer.

Ainda, pensamos que a tradução de "ethnologue" por "etnologista" atenua a naturalidade e mesmo a genuinidade do desejo de Moéma, pois soa um pouco artificial o fato de uma personagem estudante de antropologia não conhecer o 
vocabulário usual em sua área e, se ela parece não saber do que fala, o seu desejo, como negação de uma realidade que ela nem mesmo conhece muito bem, também se torna menos legítimo ${ }^{25}$.

Uma consequência diferente se verifica na tradução de "En fervente des choses mêmes" - expressão usada pelo narrador no contexto em que explicita a vontade de Moéma de partir à tribo de Aynoré - por "Fervorosa em relação às coisas em si”. Essa tradução tira da sombra a discussão que neste artigo se busca explicitar mediante as interpretações aqui adotadas. A expressão “En fervente des choses mêmes" traduz e reforça a ideia de um acesso mais direto às coisas, um conhecimento estabelecido mais pela via do sentir, das intuições do coração, do que um conhecimento mediado pela ciência. Essa ausência de mediação é captada pela expressão em português “coisas em si”. Nesse sentido, a presença da visão dicotômica do conhecimento que caracteriza a personagem Moéma ganha relevância com essa opção tradutória.

\section{Conclusão}

Diferentemente da imagem que Moéma tem de Aynoré, romantizada, idealizada, a imagem do índio que emerge da trama ironiza a conhecida projeção de valores da cultura europeia ocidental sobre o Outro, distante e, por vezes, exótico. Essa ironia toma forma no engano de Moéma em relação a Aynoré. É possível, com base nas análises feitas, delinear a imagem de um índio que não apenas não cumpre as expectativas europeias e ocidentais nele depositadas como entende essas expectativas e inventa maneiras de brincar com elas. Nesse sentido, não é descabido dizer que Aynoré trafega na alteridade de forma muito mais fluida

\footnotetext{
${ }^{25}$ Cabe observar que Lévi-Strauss, em Antropologia Estrutural (1967), ao distinguir etnologia de etnografia explica: “(...) a etnografia consiste na observação e análise de grupos humanos considerados em sua particularidade (...) e visando à reconstituição, tão fiel quanto possível, da vida de cada um deles". A etnologia, por sua vez, "utiliza de modo comparativo (...) os documentos apresentados pelo etnógrafo" e "(...) corresponde aproximadamente ao que se entende, nos países anglo-saxões (...) por antropologia social e cultural (...)" (STRAUSS 1967: 14, grifos nossos). Percebe-se, pois, que a mediação está mais presente no conceito de etnologia do que no de etnografia. Um etnógrafo realiza uma observação mais direta do que um etnólogo, que analisa documentos produzidos por outras pessoas. Em outras palavras, um etnólogo constrói seu olhar de forma ainda mais mediada pela ciência do que alguém que faz uma etnografia, pois na etnologia não se observa diretamente um grupo humano, estudam-se documentos a partir de dados colhidos por um etnógrafo. Essa distinção se reflete no uso da palavra "ethnologue" associada à busca de Moéma por uma experiência menos mediada pela ciência e mais genuína.
} 
do que Moéma, uma vez que ele não está condicionado a uma identidade única e pode jogar, ainda que com ardil, com os seus múltiplos “eus”. Moéma, em sua obsessão, consegue apenas se assustar ao ver Aynoré sendo outro que não o índio por ela projetado.

Assim, o romance de Roblès, à medida que aponta, em um primeiro momento, para imagens já conhecidas do Brasil, inova também ao mostrar que essas imagens não necessariamente se sustentam. Ou seja, ainda que em um primeiro momento elas sejam produzidas, há nelas fragilidades; o autor nos mostra o seu "avesso", os seus ângulos mortos. Nessa, como em outras histórias do romance, vemos essas imagens muito conhecidas e cristalizadas se tornarem aos poucos frágeis e se dissolverem, culminando em algum tipo de tragédia. É interessante ressaltar que Roblès, em seu processo criativo, faz uso de uma profunda ironia para engendrar essa engrenagem de construção e desconstrução de expectativas. Essa forma de conduzir o texto marca todo o romance: o narrador aponta caminhos que, no entanto, não são seguidos, gerando surpresa nos leitores e desencontros e angústias nas personagens, que por extensão atingem também os leitores. Note-se ainda que, diferentemente da constatação de Sousa (1996), no romance de Roblès o índio Aynoré não é apenas um elemento a mais na paisagem primitiva do Brasil. Não há apenas a imagem de um índio dócil, que gentilmente absorve valores chegados de fora... Ao contrário, o índio de Canoa Quebrada adota uma postura bastante ativa e age até mesmo com certo ardil.

Observou-se que, na tradução, algumas passagens atenuam discussões presentes de forma implícita no original, e outras, ao contrário, jogam luz nessas discussões. Considerando as análises como um todo, percebe-se que o registro de um Brasil exótico pode se atenuar um pouco na tradução, até mesmo pela ausência do contraste entre língua e cultura, que é uma característica marcante do original, no qual personagens brasileiros falam francês - esse contraste já é dado! Nesse sentido, se por um lado a significância do original sofre desvios (necessários) a partir da atividade tradutória, por outro a tradução vai construindo uma significância própria em seu texto. Mediante uma ênfase menor na doçura do índio, por exemplo, a tradução atenua a atmosfera romântica e idealizada da trama. 
Também o movimento de reversão de expectativas, tão nítido no original, é menos sentido na tradução, pois ao relativizar o romantismo de algumas cenas, ela suaviza o encaminhamento do leitor para a formação de um Brasil exótico, com feições de cartão postal. Na troca de significantes operada através da tradução, e, portanto, na construção de outras redes de significância, novas interpretações das passagens são anunciadas: um índio possivelmente menos marcado por imagens já conhecidas pode ser apreendido por leitores brasileiros, e o ponto de virada da narrativa talvez gere menos impacto nesses mesmos leitores. Fica, portanto, evidente a importância da tradução para as releituras de uma obra, para o aparecimento de novos direcionamentos e de novas interpretações de um texto literário.

\section{Referências bibliográficas}

AMADO, J. Capitães da Areia. 65a. ed. Rio de Janeiro: Record, 1987.

Amoroso, M. R. Mudança de Hábito. Catequese e educação para índios nos aldeamentos capuchinhos. In: Rev. bras. Ci. Soc. v. 13, n. 37. São Paulo: Junho, 1998. Disponível em:

<http://www.scielo.br/scielo.php?script=sci_arttext\&pid=S010269091998000200006>. Acesso em: 8 jun. 2017.

BeLLeR, M.; LeERSSEN, J. Imagology: the cultural construction and literary representation of national characters - A critical survey. Rodopi: Amsterdan - New York, 2007.

Berman, A. Pour une critique des traductions: John Donne. Paris: Gallimard, 1995.

BERMAN, A. La traduction et la lettre ou l'auberge du lointain. Paris: Éditions du Seuil, 1999.

CANDIDO, A. Literatura e sociedade. Estudos de teoria e história literária. São

Paulo: T.A. Queiroz Editor, 2000.

HolandA, S. B. Raízes do Brasil. 12. ed. Rio de Janeiro: José

Olympio, 1978 [1936].

CNRTL. Dicionário francês/francês online. Disponível em :

<http://www.lexilogos.com/francais_langue_dictionnaires.htm >. Acesso em: 8 jun. 2017. 
CRIAÇÃo do mundo para os índios Dessana, 2012. Disponível em:

<http://www.acropole.org.br/para-saber-mais/artigo-filosoficos/22-artigos-

simbolismo/67-artigo-simb-4.html>. Acesso em: 01 jun. 2017.

DiCıONÁRIO online de português - Murucu, 2017. Disponível em:

<https://www.dicio.com.br/murucu/>. Acesso em: 01 jun. 2017.

DiCTIONNAIRE - Vrombissement, 2017. Disponível

em:<http: //www.universalis.fr/dictionnaire/vrombissement/>. Acesso em: 01 jun. 2017.

Durão, S. R. Caramuru. Poema épico do descobrimento da Bahia. São Paulo: Martin Claret, 2011.

DURKheIM, É. As regras do método sociológico. Tradução: Paulo Neves. São

Paulo: Martins Fontes, 2007.

DYSERINCK, H. Zur Entwicklung der Komparatischen Imagologie. In: Colloquium

Helvetium. Sonderdruck, Frankfurt a. M., Peter Lang, 1988, p.19-42.

DYSERINCK, H. Sobre o desenvolvimento da imagologia. Trad. Jael Glauce da

Fonseca. In: SousA, C. Re. Coletânea de ensaios de Hugo Dyserinck I. 2005. Disponível em: <http://rellibra.com.br/pdf/imalogia1/sobre.pdf>. Acesso em: 20 set. 2016.

Flaubert, G. Três contos. Trad. Milton Hatoum e Samuel Titan Junior. São

Paulo: CosacNaify, 2004.

Hatoum, M. Relato de um certo oriente. São Paulo: Companhia das Letras, 2004.

HouAlss. Dicionário português/português online. Disponível em :

https://houaiss.uol.com.br. Acesso em: Acesso em: 8 jun. 2017.

Genette, G. Seuils. Paris : Seuil, 1987.

LAROUSSE. Dicionário Larousse online. Disponível em:

<http://www.larousse.fr/dictionnaires/francais>. Acesso: 7 jun. 2017.

L'INTERNAUTE. Dicionário francês/francês online. Disponível em:

<http://www.linternaute.com/dictionnaire/fr> Acesso em 07 jun. 2017.

MOURA, J.-M. Lire l'exotisme. Paris : Dunod, 1992.

Mouralis, B. Les contre-littératures. Paris : Presses Universitaires de France, 1975.

PAGEAUX, D.-H. Imagologie: bilan d'une recherche, perspectives de

réflexion. In: DAVOR DUKIC, H. (org.). Imagology today: achievements; challenges; perspectives. Bonn : Bouvier, 2012. 
PAGEAUX, D.-H. Littérature générale et comparée et imaginaire.

In: Anunario de la Sociedad Española de Literatura General y Comparada. № 9 , 1995, p. 81-95. Disponível em:

<https://dialnet.unirioja.es/servlet/articulo?codigo=2369056> Acesso em: 01 jun. 2017.

SAID, E. Orientalismo: o Oriente como invenção do Ocidente. Trad. Rosaura

Eichenberg. São Paulo: Companhia das Letras, 2007.

SIMÕES, M. J. Imagotipos literários: processos de (des)configuração na

imagologia literária. Coimbra: Centro de Literatura Portuguesa, 2011.

Segalen, V. Essai sur l'exotisme: une esthétique du divers et Textes sur Gaugin et l'Océanie. Paris: Fata Morgana, 1978.

SousA, C. R. Retratos do Brasil: heteroimagens literárias alemãs no Brasil. São Paulo: Arte e Ciência, 1996.

SousA, C. R. Do cá e do lá: introdução à imagologia. São Paulo:

Associação Editorial Humanitas, 2004.

ViveIROS DE CASTRO, E. Perspectival anthropology and the method of controlled equivocation. Tipití, v. 2, n.1, p. 3-22, 2004.

Viveiros de castro, E.; Sztutman, R. (Org.). Encontros. Rio de Janeiro: Beco do Azougue, 2008.

Recebido em: 27/08/2018

Aceito em: $17 / 12 / 2018$

Publicado em dezembro de 2018 